\title{
Fasudil inhibits proliferation and migration of Hep-2 laryngeal carcinoma cells
}

This article was published in the following Dove Press journal:

Drug Design, Development and Therapy

\section{Xiaowen Zhang' \\ Nan Wu ${ }^{2}$}

'Medical Research Center, Shengjing Hospital of China Medical University, Shenyang, China; ${ }^{2}$ The Core Laboratory for Public Health Science and Practice, The First Affiliated Hospital of China Medical University, Shenyang, China
Correspondence: Nan Wu

The Core Laboratory for Public Health Science and Practice, The First Affiliated Hospital of China Medical University, I55th North of Nanjing Street, Heping District, Shenyang II000I, Liaoning, China

Tel +862423269477

Fax +862423269477

Email imwunan@163.com
Background: Rho-kinase signal pathway is a new target for cancer therapy. Fasudil, a selective Rho-kinase inhibitor, is found to exert antitumor effects on several types of cancer, but whether fasudil has antitumor effects on laryngeal carcinoma is still unknown. The aim of this study was to determine the effects of fasudil on laryngeal carcinoma and explore the underlying molecular mechanisms in this process.

Methods: After treatment with fasudil, changes in biological behaviors, including the growth, proliferation, clone formation, apoptosis, and migration of human laryngeal carcinoma cells (Hep-2 cells) were observed. The influences on apoptotic protease activity factor-1 (APAF-1)mediated apoptosis pathway and the activities of matrix metalloproteinases (MMP-2 and MMP-9) were measured by Western blotting and gelatin zymography assay.

Results: Half-maximal inhibitory concentration of fasudil to Hep- 2 cells was $\sim 3.40 \times 10^{3} \mu \mathrm{M}$ (95\% CI: $\left.2.53-4.66 \times 10^{3} \mu \mathrm{M}\right)$. Moreover, fasudil treatment significantly decreased the ability of growth, proliferation, clone formation, and migration of Hep- 2 cells, while remarkably increased the apoptosis rate. Furthermore, the expressions of APAF-1, caspase-9, and caspase- 3 significantly increased in fasudil treatment group. Meanwhile, fasudil led to a remarkable decrease in the expressions and activities of MMP-2 and MMP-9.

Conclusion: Our findings first demonstrate that fasudil not only inhibits the proliferation of laryngeal carcinoma cells through activating APAF-1-mediated apoptosis pathway, but also prevents migration by inhibiting the activities of MMP-2 and MMP-9. Therefore, fasudil is an attractive antitumor drug candidate for the treatment of laryngeal carcinoma.

Keywords: fasudil, laryngeal carcinoma, apoptosis, apoptotic protease activity factor-1, matrix metalloproteinase

\section{Introduction}

Laryngeal carcinoma is one of the most common head and neck cancers worldwide, and nearly 90\% laryngeal carcinoma cases were diagnosed as laryngeal squamous cell carcinoma (LSCC) according to the pathology diagnosis. ${ }^{1}$ Although the surgery and radiotherapy are widely used in the treatment of LSCC, its overall survival rate has never changed (at $\sim 35 \%-70 \%$ ) over the past several decades. ${ }^{2}$ Therefore, there is a great need to identify the molecular pathways that are essential for the proliferation and migration of LSCC, and develop pharmacological compounds that can effectively block these pathways.

Rho-kinase (ROCK) is known as an effector of the small GTPase Rho and consists of 2 isoforms, ROCK1 and ROCK2. ROCK executes multiple cellular functions, including smooth muscle contraction, actin cytoskeleton organization, cell adhesion, and cell motility. ${ }^{3,4}$ There is growing evidence showing that Rho/ROCK signal pathway is activated in tumors and plays a key role in the proliferation and migration of cancer cells. ${ }^{5-7}$ Moreover, Rho GTPases are required for Ras-mediated oncogenic 
transformation. ${ }^{8}$ More importantly, recent studies have demonstrated that Rho/ROCK signal pathway is a new target for cancer therapy..$^{9,10}$

Fasudil, a selective inhibitor of ROCK, has been approved by Japan and China government to use in the clinical treatment of cerebral vasospasm. ${ }^{11}$ Moreover, fasudil is also used in the treatment of pulmonary hypertension ${ }^{12}$ and age-related or neurodegenerative memory loss. ${ }^{13}$ Most interestingly, fasudil is found to exert antitumor effects on several types of cancer. ${ }^{14-19}$ However, whether fasudil causes tumorigenesis in LSCC is still unknown. Therefore, in the current study, we investigated the effects of fasudil on the growth, proliferation, clone formation, apoptosis, and migration of LSCC in vitro, and further explored the underlying molecular mechanisms involved in this process.

\section{Materials and methods Drug}

Fasudil was purchased from Meilun Co., Ltd. (Dalian, China) (Purity: high-performance liquid chromatography $>99 \%$. CAS\#: 105628-07-7. Molecular formula: $\mathrm{C}_{14} \mathrm{H}_{17} \mathrm{~N}_{3} \mathrm{O}_{2} \mathrm{~S} . \mathrm{HCl}$. Molecular weight: 327.83$)$. The fasudil powder was dissolved in phosphate buffered solution (PBS) to make a stock solution at the final concentration of $100 \mathrm{mg} / \mathrm{mL}$.

\section{Cell line and cell culture}

Human laryngeal carcinoma cell line (Hep-2) was obtained from the Cell Biology Institute of Shanghai, Chinese Academy of Science and cultured in Roswell Park Memorial Institute (RPMI) 1640 (GIBCO, Los Angeles, CA, USA) with 10\% fetal bovine serum (FBS; Hyclone, Logan, UT, USA), 100 units $/ \mathrm{mL}$ penicillin and $100 \mu \mathrm{g} / \mathrm{mL}$ streptomycin in a humidified atmosphere at $37^{\circ} \mathrm{C}$ with $5 \% \mathrm{CO}_{2}$.

\section{Growth inhibitory assay}

Hep- 2 cells were seeded in 96-well microplates $\left(2 \times 10^{3}\right.$ cells/ well in $100 \mu \mathrm{L}$ medium). Fasudil was added to the cultures at a concentration of $0,9.15,4.58 \times 10^{1}, 9.15 \times 10^{1}, 4.58 \times 10^{2}$, $9.15 \times 10^{2}, 2.29 \times 10^{3}, 4.58 \times 10^{3}, 9.15 \times 10^{3}, 1.53 \times 10^{4}$, and $2.29 \times 10^{4} \mu \mathrm{M}$ and cultures were incubated for $6 \mathrm{~h}$. The medium was discarded and $10 \mu \mathrm{L}$ tetrazolium dye (MTT) solution $(5 \mathrm{mg} / \mathrm{mL}$ in PBS) was added to each well. Plates were incubated at $37^{\circ} \mathrm{C}$ for an additional $4 \mathrm{~h}$. Dimethyl sulphoxide (DMSO) $(150 \mu \mathrm{L})$ was added to dissolve the formazan crystals that had formed. The optical density (OD) was measured on a microplate reader (Bio-Rad, Hercules, CA, USA) with a $490 \mathrm{~nm}$ filter. MTT and cells treated with
DMSO $(0.1 \%)$ were the control for $100 \%$ survival. The percentage of growth inhibition was expressed as growth in control conditions minus growth in test conditions divided by growth in control conditions. At least 6 independent experiments were performed for each experimental condition. The concentration of $4.58 \times 10^{3} \mu \mathrm{M}$ used in this study was determined based on this data.

\section{Tumor cell morphology study}

Hep-2 cells were seeded in 6-well chamber slides with growth medium overnight at $37^{\circ} \mathrm{C}$. The next day, the cells were treated with $4.58 \times 10^{3} \mu \mathrm{M}$ fasudil for $6 \mathrm{~h}$, and then washed with PBS, fixed with $4 \%$ paraformaldehyde at room temperature for $30 \mathrm{~min}$, washed with $\mathrm{PBS}$ and stored at $4^{\circ} \mathrm{C}$. After that, the cells were permeabilized with $0.1 \%$ Triton $\mathrm{X}-100$ in PBS at room temperature for $5 \mathrm{~min}$, washed with PBS, blocked with $5 \%$ bovine serum albumin at $4{ }^{\circ} \mathrm{C}$ for $30 \mathrm{~min}$, washed with PBS, incubated with mouse anti- $\alpha$-Tubulin antibody (1:100 dilution; Boster, Wuhan, China) at $4^{\circ} \mathrm{C}$ overnight in humidified chamber. After washing with PBS, the cells were stained with fluorescein-conjugated affinipure goat anti-mouse IgG (1:100 dilution; ZSGB-BIO, Beijing, China) at $37^{\circ} \mathrm{C}$ for $45 \mathrm{~min}$ under the conditions of protection from light, then washed with PBS again, and finally, stained with propidiumiodide for $5 \mathrm{~min}$ (1:100 dilution). Slides were air dried and mounted with 50\% glycerol. Fluorescence images were photographed using the $\times 40$ objective.

\section{Cell proliferation and colony formation assay}

After $6 \mathrm{~h}$ of incubation with $4.58 \times 10^{3} \mu \mathrm{M}$ fasudil, the cells were collected for cell proliferation assay. For cell proliferation analysis, $2-3 \times 10^{3}$ Hep- 2 cells were plated into 96-well plates in triplicate. Cells were then cultured for 1, 2, 3, and 4 days. The absorbance at $490 \mathrm{~nm}$ was measured after incubation of the cells with $10 \mu \mathrm{L}$ sterile MTT dye $(0.5 \mathrm{mg} / \mathrm{mL}$, Sigma, St Louis, MO, USA) for $4 \mathrm{~h}$ at $37^{\circ} \mathrm{C}$ and $150 \mu \mathrm{L}$ DMSO for $15 \mathrm{~min}$. Then the cell growth rate was expressed as the values of OD at $490 \mathrm{~nm}$. In the colony formation assay, after treating with $1.5 \mathrm{mg} / \mathrm{mL}$ fasudil for $6 \mathrm{~h}$, Hep- 2 cells were seeded at a density of $3 \times 10^{3}$ cells in $35 \mathrm{~mm}$ Petri dishes in triplicate and maintained in RPMI 1640 with $10 \%$ FBS. After 7 days, the colonies were fixed with methanol for $30 \mathrm{~min}$, washed with PBS, dried and stained with H\&E for $20 \mathrm{~min}$, and scored using a microscope. Colony formation for each condition was calculated in relation to the values obtained from the mock and the scramble-treated control cells. 


\section{Cell apoptosis assay}

Flow cytometric analyses were performed to measure the cell apoptosis for treated and untreated cells. After treatment with $4.58 \times 10^{3} \mu \mathrm{M}$ fasudil for $6 \mathrm{~h}$, Hep- 2 cells were collected and then stained with fluorescein isothiocyanateconjugated annexin- $\mathrm{V}$ and propidium iodide for $10 \mathrm{~min}$ at room temperature according to manufacturer's instructions (Annexin V-EGFP Apoptosis Detection Kit, KeyGEN, Nanjing, China). Data acquisition and analysis were performed by flow cytometry using Cell Quest software (fluorescence-activated cell sorting [FACS] calibur, BectonDickinson, Sparks, MD, USA).

\section{Cell migration assay}

After treatment with $4.58 \times 10^{3} \mu \mathrm{M}$ fasudil for $6 \mathrm{~h}$, Hep- 2 cells were collected for a transwell migration assay. For the migration experiment, $100 \mathrm{~mL}$ cell suspension containing $7 \times 10^{4}$ cells were separately planted onto transwell upper chambers in triplicate and $1 \mathrm{~mL}$ RPMI-1640 medium containing $20 \%$ FBS was supplemented into lower chambers. Chambers were incubated at $37^{\circ} \mathrm{C}$ with $5 \% \mathrm{CO}_{2}$ for $24 \mathrm{~h}$, and washed with PBS. The cells invading the lower surface and attaching to the membrane were fixed in $4 \%$ paraformaldehyde for 5 min, stained with $\mathrm{H} \& \mathrm{E}$, washed with PBS thrice, and examined under a microscope. Five visual fields on each microfilm were randomly selected for cell counting.

\section{Gelatin zymography assay}

Gelatin zymography was performed to determine the activity of matrix metalloproteinases (MMP-2 and MMP-9) using Gelatin Zymography Assay Kit (APPLYGEN, Beijing, China) according to the manufacturer's recommendation. The details have been described in previous article. ${ }^{17}$ The band intensity represented the activities of MMP-2 and MMP-9.

\section{Western blot analysis}

After incubation with $4.58 \times 10^{3} \mu \mathrm{M}$ fasudil for $6 \mathrm{~h}$, protein was extracted from Hep-2 cells using a protein extraction reagent (Beyotime, Shanghai, China) and protein concentration was measured using the bicinchoninic acid Protein Assay kit (Beyotime). The aliquots of protein $(50 \mu \mathrm{g})$ were separated by $10 \%$ sodium dodecyl sulfate-polyacrylamide gel electrophoresis and transferred to polyvinyl difluoride membrane. The membrane was then blocked with $5 \%$ non-fat milk overnight at $4^{\circ} \mathrm{C}$, and incubated with apoptotic protease activity factor-1 (APAF-1) (1:500 dilution; Abcam, Cambridge, UK), caspase-3 (1:500 dilution; Abcam), caspase-9 (1:500 dilution; Abcam), MMP-2
(1:500 dilution; Abcam), MMP-9 (1:500 dilution; Abcam), and $\beta$-actin (1:500 dilution; ZhongShan, Beijing, China) antibodies for $2 \mathrm{~h}$, followed by incubation with horseradish peroxidasecoupled goat anti-rabbit antibody (1:2,000 dilution; ZhongShan) or horseradish peroxidase-coupled goat anti-mouse antibody (1:10,000 dilution; ZhongShan) for $1 \mathrm{~h}$. Detection was performed by enhanced chemi-luminescence using a Western blotting luminological reagent (Santa Cruz Biotechnology, Santa Cruz, CA, USA) according to the manufacturer's instructions. $\beta$-actin was used as a reference protein. Relative densitometry was performed using a computerized software package (NIH Image 1.63 software; https://imagej.nih.gov/ij/).

\section{Statistical analysis}

The results are presented as means \pm SD. Statistical analyses were performed with unpaired $t$-tests using SPSS 17.0 software (IBM Corp., Armonk, NY, USA). $P$-values $<0.05$ were considered significant. Confidence intervals for the effective dose of fasudil were performed using probit regression analysis.

\section{Results \\ Fasudil inhibited cell growth in Hep-2 cells in vitro}

As shown in Table 1, for Hep-2 cells treated with fasudil at the dose of $0,9.15,4.58 \times 10^{1}, 9.15 \times 10^{1}, 4.58 \times 10^{2}, 9.15 \times 10^{2}$, $2.29 \times 10^{3}, 4.58 \times 10^{3}, 9.15 \times 10^{3}, 1.53 \times 10^{4}$, and $2.29 \times 10^{4} \mu \mathrm{M}$, the growth inhibition rates were $0,3.3 \%, 6.8 \%, 10.4 \%, 20.9 \%$, $30.7 \%, 43.8 \%, 55.2 \%, 65.2 \%, 73.6 \%$, and $83.6 \%$, respectively, which presented in a dose-dependent manner. Probit regression analysis showed that the half-maximal inhibitory concentration $\left(\mathrm{IC}_{50}\right)$ of fasudil to Hep-2 cells was $\sim 3.40 \times 10^{3} \mu \mathrm{M}\left(95 \%\right.$ CI: $2.53-4.66 \times 10^{3} \mu \mathrm{M}$; Figure 1$)$.

\section{Effect of fasudil on the morphological changes of Hep-2 cells}

The Hep- 2 cells were treated with $4.58 \times 10^{3} \mu \mathrm{M}$ fasudil for $6 \mathrm{~h}$ and then stained with $\alpha$-Tubulin to visualize cytoskeletal elements in the cell cytoplasm. The treated Hep-2 cells lost their original polygonal morphology and adopted more of a stellate morphology with an increasing number of cell processes. The cell body became thinner, elongated and the processes presented as filopodia (Figure 2).

\section{Effect of fasudil on cell proliferation of Hep-2 cells}

As shown in Figure 3, the relative proliferation rate in fasudil treatment group was significantly reduced compared with 


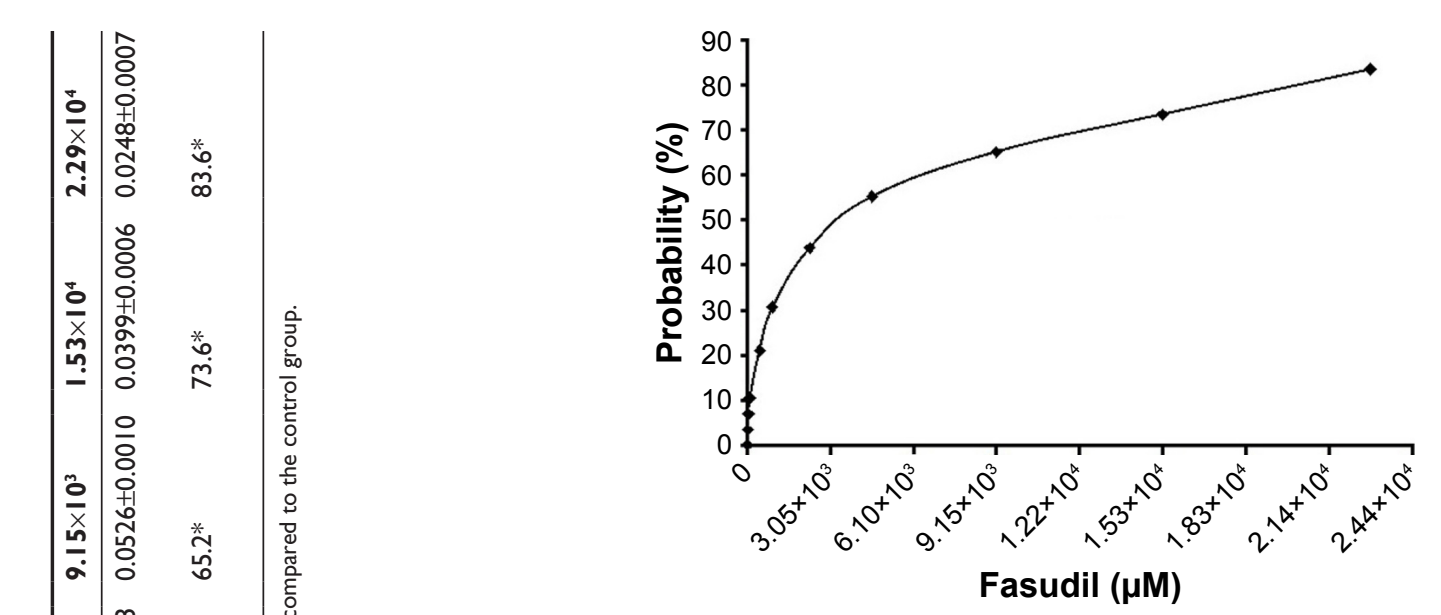

Figure I Probit regression analysis.

Note: Probit regression analysis (SPSS 17.0; IBM Corp., Armonk, NY, USA) showed that the $1 \mathrm{IC}_{50}$ of fasudil for Hep-2 cells was $\sim 3.40 \times 10^{3} \mu \mathrm{M}$ and $95 \% \mathrm{Cl}$ was $2.53-$ $4.66 \times 10^{3} \mu \mathrm{M}$.

control group $(P<0.05)$, which indicated that fasudil significantly inhibited Hep-2 cell proliferation.

\section{Effect of fasudil on colony formation of Hep-2 cells}

As shown in Figure 4, the colony formation rate in fasudil treatment group was significantly decreased compared with control group $(P<0.05)$, which suggested that fasudil strongly inhibited the ability of colony formation in Hep-2 cells.

\section{Effect of fasudil on early apoptosis of Hep-2 cells}

As shown in Figure 5, the early apoptosis rate in fasudil treatment group was significantly higher than control group $(P<0.05)$, which indicated that fasudil strongly induced early apoptosis in Hep-2 cells.

\section{Effect of fasudil on cell migration of Hep-2 cells}

The result of transwell assay showed that the numbers of migrated Hep-2 cells/field were significantly decreased in fasudil treatment group compared with control group $(P<0.05)$,
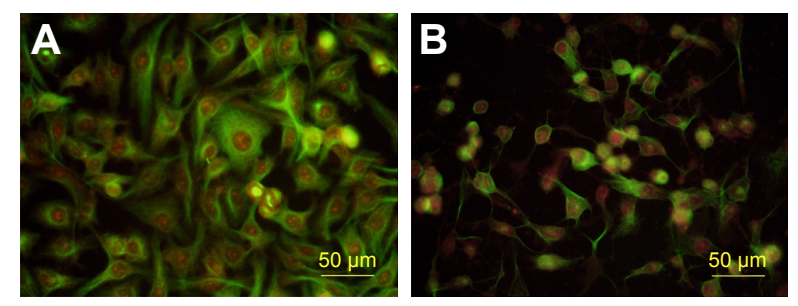

Figure 2 Effects of fasudil on morphologic changes in Hep-2 cells. Notes: Hep- 2 cells were treated with $4.58 \times 10^{3} \mu \mathrm{M}$ fasudil (B), or medium alone (A) for $6 \mathrm{~h}$ and then stained for $\alpha$-tublin (green) and nucleus (red) to visualize the change of cytoskeleton. Fluorescence images were taken with $\times 40$ objective. 


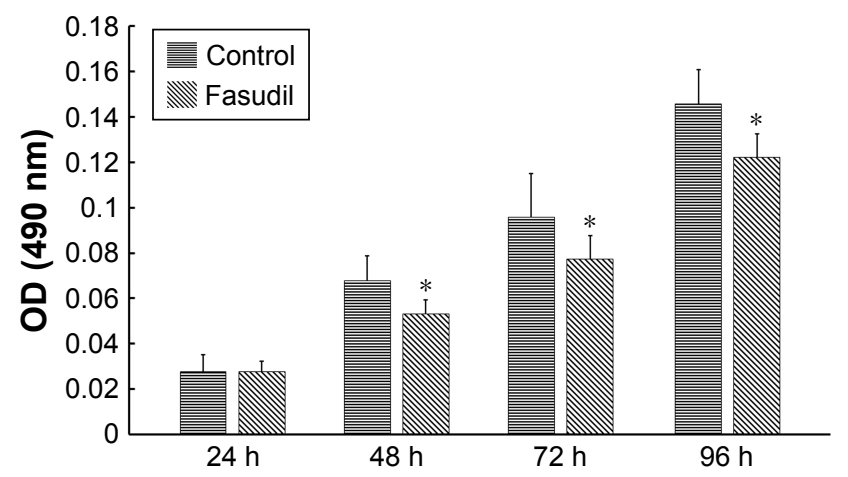

Figure 3 Effects of fasudil on proliferation of Hep-2 cells.

Notes: The inhibitory effects of fasudil $\left(4.58 \times 10^{3} \mu \mathrm{M}\right)$ on proliferation of Hep-2 cells were measured for 4 consecutive days. The values of $O D$ at $490 \mathrm{~nm}$ were used as the ordinate axis. Data are representative of three independent experiments. $* P<0.05$ vs control.

Abbreviation: OD, optical density.

which indicated that fasudil significantly suppressed migration of Hep-2 cells (Figure 6).

\section{Fasudil upregulated APAF-I, caspase-9, and caspase- 3 of Hep-2 cells}

As shown in Figure 7, Western blot analysis revealed that the levels of APAF-1, caspase-9, and caspase-3 were increased significantly in Hep-2 cells treated with fasudil, compared with control group $(P<0.05)$.

\section{Fasudil inhibited MMP-2 and MMP-9 of Hep-2 cells}

Western blot analysis displayed that the levels of MMP-9 and MMP-2 protein were remarkably decreased by fasudil treatment $(P<0.05$; Figure 8$)$ and the result of gelatin zymography showed that the activities of MMP-9 and MMP-2 were also significantly decreased compared with control $(P<0.05$; Figure 9). These 2 results indicated that fasudil inhibited the MMP-2 and MMP-9 of Hep-2 cells.

\section{Discussion}

Rho/ROCK signal pathway has been demonstrated to contribute to the cancer development and progression. ${ }^{20}$ More interestingly, pharmacological inhibition of Rho/ROCK signal pathway by fasudil alone ${ }^{14-19}$ or in combination with chemotherapy ${ }^{21}$ displays powerful antitumor effects on several types of cancer and the underlying mechanisms might be linked to its regulation on the contraction, adhesion, migration, proliferation, and apoptosis of cancer cells. ${ }^{21,22}$ However, few data concerning the antitumor effect on laryngeal carcinoma cells are recorded.

In the present study, we reported the antitumor activities of fasudil in human laryngeal carcinoma cells (Hep-2 cells) for the first time. We found that fasudil induced dramatic morphologic changes in Hep- 2 cells. After $6 \mathrm{~h}$ of fasudil treatment, the cell bodies became round and some cells detached from the plastic surface. This result agreed with previously published studies, showing that fasudil caused morphologic changes in MDA-MB-231 breast carcinoma cells and HT1080 fibrosarcoma cells. ${ }^{14}$ Therefore, our study further supported the fact that Rho/ROCK pathway plays an important role in regulating reorganization and assembly of the cytoskeleton in cancer cells.

There are still some controversies in literature with regard to whether fasudil can inhibit the growth and proliferation of cancer cells. Ying et al found that fasudil or fasudil-OH did not inhibit the proliferation of MDA-MB-231 or HT1080 cells when grown in culture dishes, and they suggested that fasudil exerts its antitumor activities by affecting tumor dissemination and metastasis rather than directly affecting cellular proliferation. ${ }^{14}$ Furthermore, Y-27632, another ROCK inhibitor, did not show any inhibition effect on the proliferation of MM1, neuroblastoma and Walker 256 cells either, ${ }^{19,23,24}$ which further supported the point that Y-27632 did not have any inhibition on the proliferation of cancer cell.
A

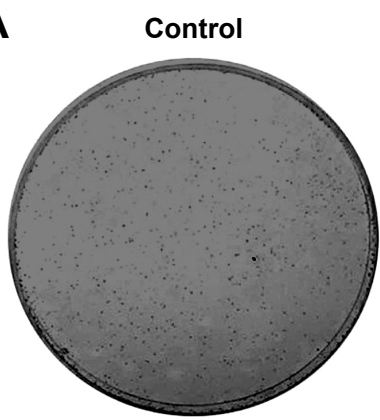

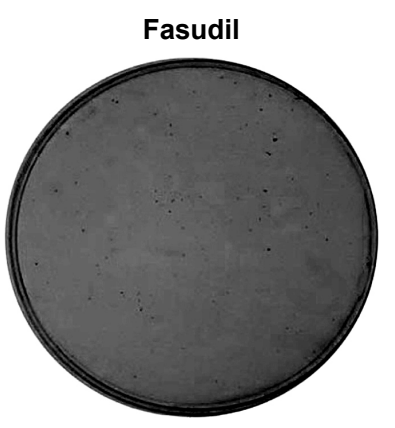

B

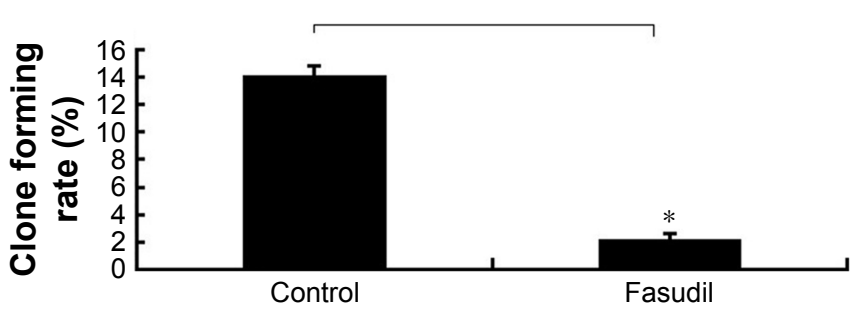

Figure 4 Effects of fasudil on colony formation of Hep-2 cells.

Notes: The clone formations were harvested after 7 days and the number of clone formation was counted. The clone formation rate is the number of clone formation

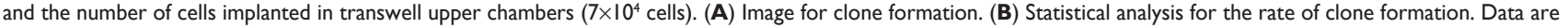
representative of three independent experiments. $* P<0.05$ vs control. 

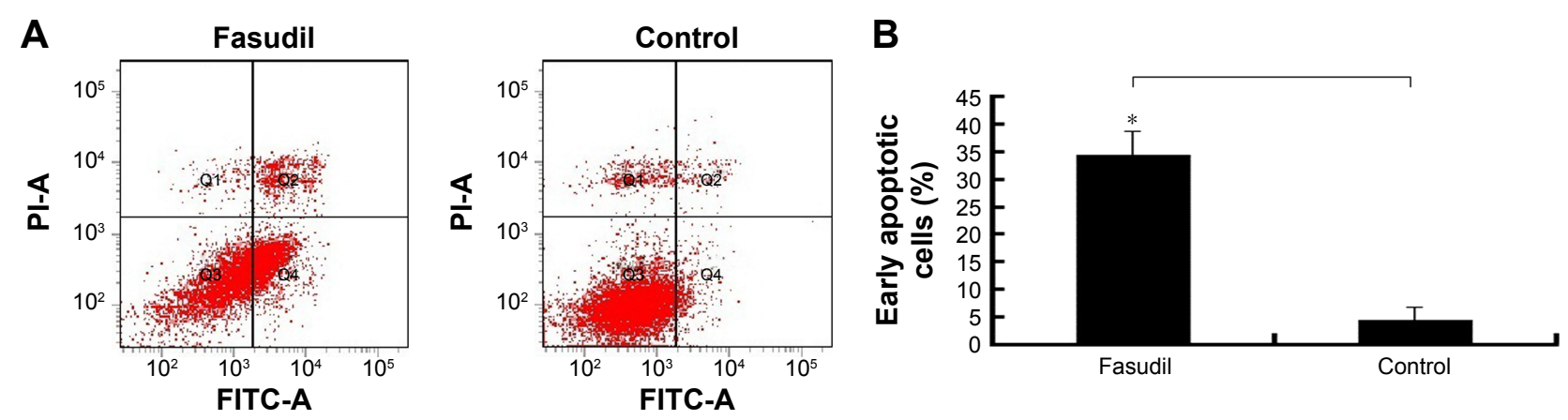

Figure 5 Effects of fasudil on early apoptosis of Hep-2 cells.

Notes: After treatment with $4.58 \times 10^{3} \mu \mathrm{M}$ fasudil for $6 \mathrm{~h}$, Hep-2 cells were collected and stained with annexin-V and PI. (A) Image for flow cytometric analyses and cells in the lower right quadrant (Q4) represents early apoptosis cells. (B) Statistical analysis for the early apoptosis rate. Data were representative of one of three independent assays. ${ }^{*} P<0.05$ vs control.

Abbreviations: FITC, fluorescein isothiocyanate; PI, propidium iodide.

However, in this study, we showed that fasudil inhibited cell growth in Hep-2 cells in a dose-dependent manner. Besides the effect of fasudil on cell growth, we observed that fasudil prevented the proliferation of Hep-2 cells, mirroring data obtained in NCI-H446, T98G, and U251 cells. ${ }^{15,17}$ The significant decrease of cell number implicated that Hep-2 cells treated with fasudil might have undergone apoptosis. So, we further studied whether fasudil might also induce apoptosis in Hep-2 cells. In the present study, we found that fasudil could lead to a remarkable increase in apoptosis in Hep-2 cells. Similar results were also reported in small cell lung cancer, ${ }^{15}$ hepatocellular carcinoma, ${ }^{25}$ urothelial cancer, ${ }^{26}$ and acute myeloid leukemia cells. ${ }^{27}$ These evidences supported the view that the inhibition of ROCK could induce apoptosis. However, there are still some paradoxes in literature on the Rho/ROCK signal pathway in the modulation of apoptosis. ${ }^{22}$ For instance, He et al reported that inhibition of Rho/ROCK signal pathway upregulated anti-apoptotic family members and inhibited caspase activation. ${ }^{28}$ Similarly, Street et al reported that the inhibition of ROCK by Y-27632 upregulated the anti-apoptotic protein $(\mathrm{Bcl} 2)$, and downregulated the proapoptotic protein (Bik, Bad, Fas, and FasL) in cisplatin-treated neuroblastoma cells. ${ }^{29}$ Furthermore, in our previous study, we provided a direct evidence that the inhibition of ROCK by fasudil decreased the number of apoptosis cell in the condition of myocardial ischemia reperfusion injury. ${ }^{30} \mathrm{We}$ speculate that these obvious discrepancies may be attributed to the difference in specific contexts, such as different tissues and cells.

APAF-1 plays a crucial role in mitochondria-mediated apoptosis. APAF-1 participates in forming a large complex, namely apoptosome. The initiator caspase, caspase- 9 , is activated through a protein-protein interaction with the apoptosome. The effector caspases, such as caspase-3, are activated through cleavage by the initiator caspase and thus, lead to cell apoptosis. ${ }^{31}$ In the present study, we observed that the expressions of APAF-1, caspase-9, and caspase-3 were significantly increased in Hep-2 cells with fasudil, and they were consistent with previous data derived from the apoptotic-FACS (Figure 5). Taken together, our studies indicated that APAF-1 and caspase-dependent apoptosis
A

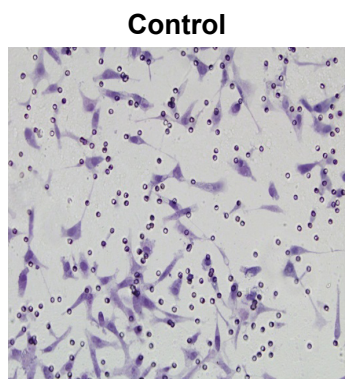

Fasudil

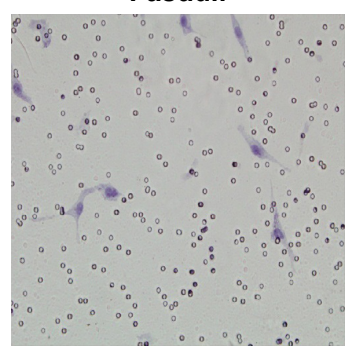

B

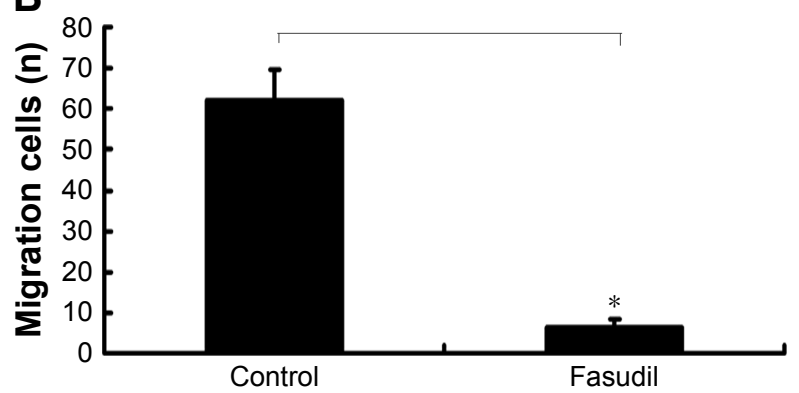

Figure 6 Effects of fasudil on migration of Hep-2 cells.

Notes: After treatment with $4.58 \times 10^{3} \mu \mathrm{M}$ fasudil, the number of Hep-2 cells migration was decreased significantly. (A) Image for cell migration. Magnification $\times 400$. (B) Statistical analysis for the number of migration cells. Data are representative of three independent experiments. $* P<0.05$ vs control. 
A

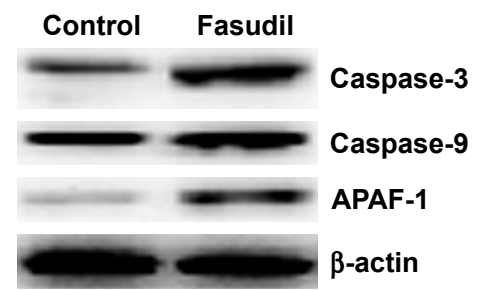

B

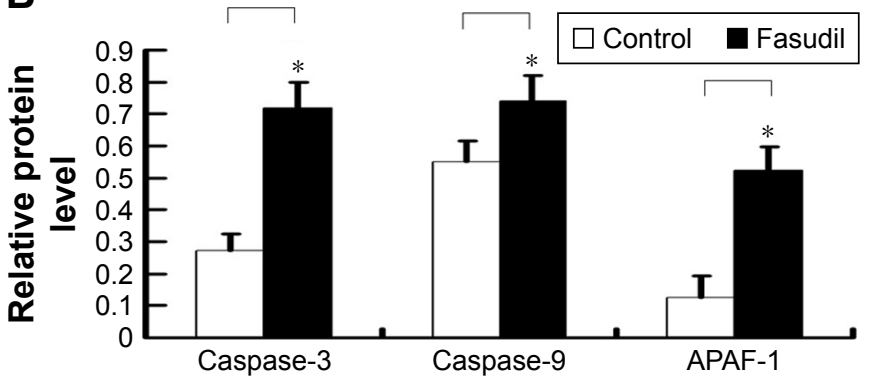

Figure 7 Protein expression of APAF-I, caspase- 9 and caspase- 3 measured by Western blot.

Notes: After incubated with fasudil $\left(4.58 \times 10^{3} \mu \mathrm{M}\right)$ for $6 \mathrm{~h}$, cells were collected and subjected to Western blot analyses to measure the expressions of APAF-I, caspase- 9 and caspase-3. (A) The image for protein band. (B) Statistical analysis for the expressions of APAF-I, caspase-9, and caspase-3. Relative protein level represents the expression of target protein normalized to a reference protein ( $\beta$-actin). Data are representative of three independent experiments. $* P<0.05$ vs control.

Abbreviation: APAF-I, apoptotic protease activity factor-I.

might contribute to fasudil-mediated anti-proliferation/ anti-survival effects on Hep-2 cells.

Previous studies have shown that Rho/ROCK pathway plays a key role in the migration and invasion of cancer cells. ${ }^{32,33}$ Fasudil may inhibit the migration of several types of cancer cells, including breast cancer cells, ${ }^{14}$ glioblastoma cells, ${ }^{17}$ and non-small cell lung cancer cells. ${ }^{34,35}$ However, whether fasudil can inhibit the migration of Hep-2 cells is still not known up to date. In this study, we reported that fasudil significantly inhibited the migration of Hep- 2 cells. Growing evidence demonstrates that MMP-2 and MMP-9 are involved in the progression of human malignancies. ${ }^{36}$ Specifically, MMP-2 along with MMP-9 is capable of degrading type IV collagen, the most abundant component of the basement membrane and thus, leading to the degradation of the basement membrane. ${ }^{37}$ Degradation of the basement membrane is considered as an essential step for the migration of cancer cells. ${ }^{38}$ So MMP-2 and MMP-9 can facilitate tumor progression and are considered as biomarkers for tumor migration and invasion. ${ }^{39}$ Our experiment further showed that fasudil significantly downregulated the expressions and activities of MMP-2 and MMP-9. The result is in line with previous findings in other cancer cell lines. ${ }^{15,17,40}$ These data suggested that fasudil prevented the migration of Hep-2 cells. The underlying mechanism may be involved in repressing the activation of MMP-2 and MMP-9.

One limitation of our study was that we only demonstrated the antitumor effect of fasudil in Hep-2 cells, but whether fasudil has antitumor effect on animals was not determined. Therefore, its antitumor effect on human laryngeal carcinoma xenograph in nude mice should be further tested.

\section{Conclusion}

In conclusion, our results demonstrate that fasudil not only inhibits the proliferation of laryngeal carcinoma cells through activating APAF-1-mediated apoptosis pathway, but also prevents migration by inhibiting the activity of MMP-2 and MMP-9. Considering that fasudil is approved for human use and tolerated without serious adverse reactions, it is an attractive antitumor drug candidate in the treatment of LSCC.
A

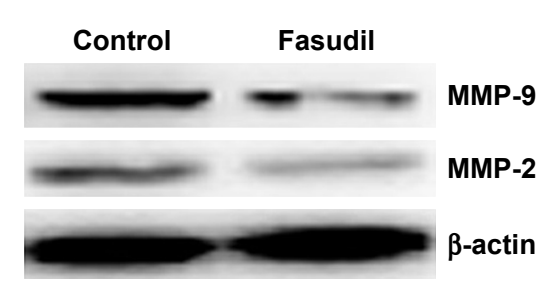

B

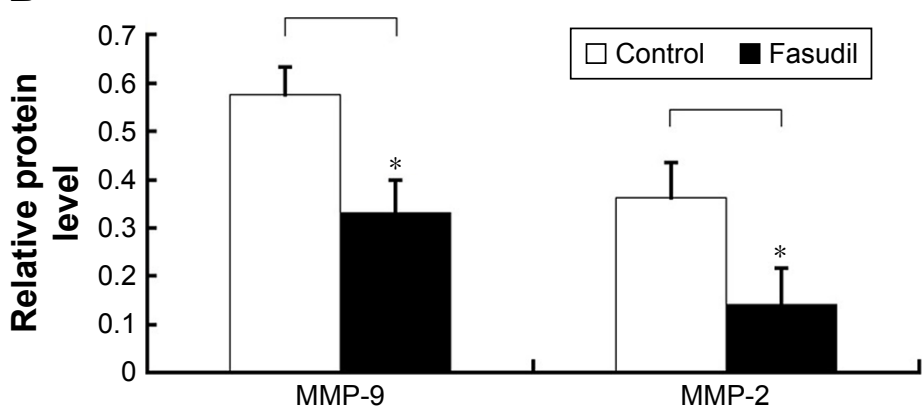

Figure 8 Protein expression levels of MMP-2 and MMP-9 measured by Western blot.

Notes: After pretreatment with fasudil $\left(4.58 \times 10^{3} \mu \mathrm{M}\right)$ for $6 \mathrm{~h}$, cells were collected and subjected to Western blot analyses to measure the expressions of MMP-2 and MMP-9. (A) The image for protein band. (B) Statistical analysis for the expressions of MMP-2 and MMP-9. Relative protein level represents the expression of target protein normalized to a reference protein ( $\beta$-actin). Data are representative of three independent experiments. $* P<0.05$ vs control. 
A

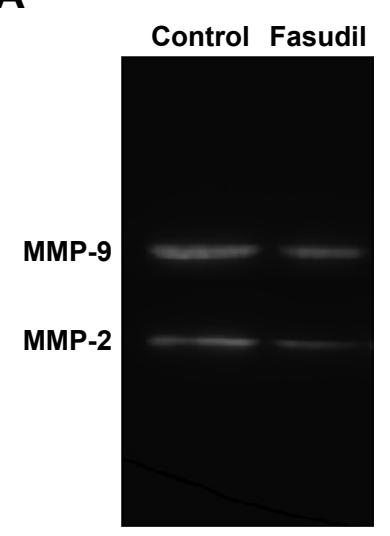

B

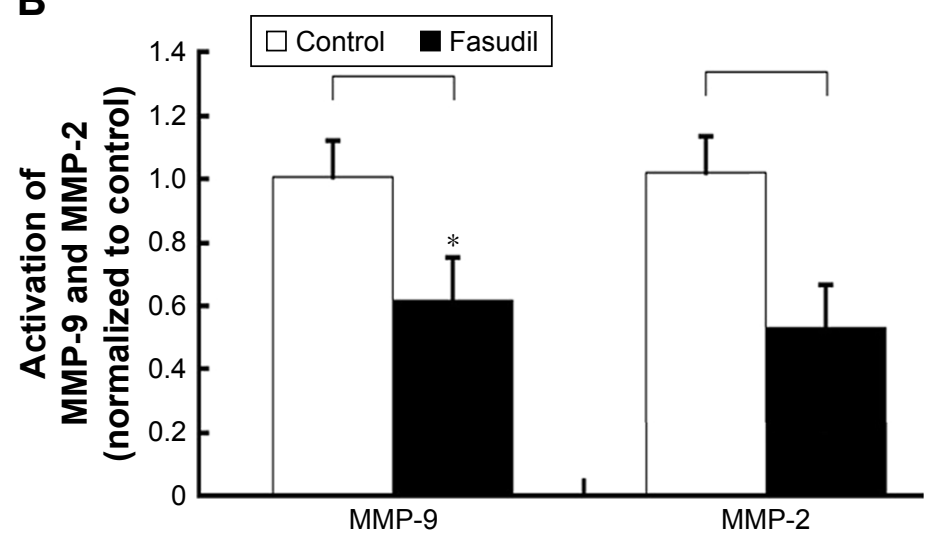

Figure 9 Activities of MMP-2 and MMP-9 measured by gelatin zymography analyses.

Notes: After pretreatment with fasudil $\left(4.58 \times 10^{3} \mu \mathrm{M}\right)$ for $6 \mathrm{~h}$, cells were collected and subjected to gelatin zymography analyses to measure the activities of MMP-2 and MMP-9. (A) The image for gelatin zymography. The activities of MMP-2 and MMP-9 appeared as clear bands against a black background. (B) Statistical analysis for the activities of MMP-2 and MMP-9. Data are representative of three independent experiments. $* P<0.05$ vs control.

\section{Disclosure}

The authors report no conflicts of interest in this work.

\section{References}

1. Siegel RL, Miller KD, Jemal A. Cancer statistics, 2016. CA Cancer J Clin. 2016;66(1):7-30.

2. Steuer CE, El-Deiry M, Parks JR, Higgins KA, Saba NF. An update on larynx cancer. CA Cancer J Clin. 2017;67(1):31-50.

3. Amano M, Ito M, Kimura K, et al. Phosphorylation and activation of myosin by Rho-associated kinase (Rho-kinase). J Biol Chem. 1996; 271(34):20246-20249.

4. Wettschureck N, Offermanns S. Rho/Rho-kinas mediated signal in physiology and pathophysiology. J Mol Med. 2002;80(10):629-638.

5. Matsuoka T, Yashiro M. Rho/ROCK signaling in motility and metastasis of gastric cancer. World J Gastroenterol. 2014;20(38):13756-13766.

6. Fritz G, Just I, Kaina B. Rho-GTPases are over-expressed in human tumors. Int J Cancer. 1999;81(5):682-687.

7. Burbelo P, Wellstein A, Pestell RG. Altered Rho GTPase signal pathways in breast cancer cells. Breast Cancer Res Treat. 2004;84(1):43-48.

8. Izawa I, Amano M, Chihara K, Yamamoto T, Kaibuchi K. Possible involvement of the inactivation of the Rho-Rho-kinase pathway in oncogenic Ras-induced transformation. Oncogene. 1998;17(22):2863-2871.

9. Mali RS, Ramdas B, Ma P, et al. Rho kinase regulates the survival and transformation of cells bearing oncogenic forms of KIT, FLT3, and BCR-ABL. Cancer Cell. 2011;20(3):357-369.

10. Lin Y, Zheng Y. Approaches of targeting Rho GTPases in cancer drug discovery. Expert Opin Drug Discov. 2015;10(9):991-1010.

11. Suzuki Y, Shibuya M, Satoh S, Sugiyama H, Seto M, Takakura K. Safety and efficacy of fasudil monotherapy and fasudil-ozagrel combination therapy in patients with subarachnoid hemorrhage: sub-analysis of the post-marketing surveillance study. Neurol Med Chir. 2008;48(6): 241-247.

12. Doggrell SA. Rho-kinase inhibitors show promise in pulmonary hypertension. Expert Opin Investig Drugs. 2005;14(9):1157-1159.

13. Huentelman MJ, Stephan DA, Talboom J, et al. Peripheral delivery of a ROCK inhibitor improves learning and working memory. Behav Neurosci. 2009;123(1):218-223.

14. Ying H, Biroc SL, Li WW, et al. The Rho kinase inhibitor fasudil inhibits tumor progression in human and rat tumor models. Mol Cancer Ther. 2006;5(9):2158-2164.

15. Yang X, Di J, Zhang Y, et al. The Rho-kinase inhibitor inhibits proliferation and metastasis of small cell lung cancer. Biomed Pharmacother. 2012;66(3):221-227.
16. Yang X, Zhang Y, Wang S, Shi W. Effect of fasudil on growth, adhesion, invasion, and migration of 95D lung carcinoma cells in vitro. Can J Physiol Pharmacol. 2010;88(9):874-879.

17. Deng L, Li G, Li R, Liu Q, He Q, Zhang J. Rho-kinase inhibitor, fasudil, suppresses glioblastoma cell line progression in vitro and in vivo. Cancer Biol Ther. 2010;9(11):875-884.

18. Miyamoto C, Maehata Y, Motohashi K, et al. Fasudil, a Rho kinase inhibitor, suppresses tumor growth by inducing CXCL14/BRAK in head and neck squamous cell carcinoma. Biomed Res. 2014;35(6): 381-388.

19. Itoh K, Yoshioka K, Akedo H, Uehata M, Ishizaki T, Narumiya S. An essential part for Rho-associated kinase in the transcellular invasion of tumor cells. Nat Med. 1999;5(2):221-225.

20. Chang YW, Bean RR, Jakobi R. Targeting RhoA/Rho kinase and p21activated kinase signaling to prevent cancer development and progression. Recent Pat Anticancer Drug Discov. 2009;4(2):110-124.

21. Vennin C, Chin VT, Warren SC, et al. Transient tissue priming via ROCK inhibition uncouples pancreatic cancer progression, sensitivity to chemotherapy, and metastasis. Sci Transl Med. 2017;9(384):eaai8504.

22. Wei L, Surma M, Shi S, Lambert-Cheatham N, Shi J. Novel insights into the roles of rho kinase in cancer. Arch Immunol Ther Exp. 2016;64(4): 259-278.

23. Hirose M, Ishizaki T, Watanabe N, et al. Molecular dissection of the Rho-associated protein kinase (p160ROCK)-regulated neurite remodeling in neuroblastoma N1E-115 cells. J Cell Biol. 1998;141(7): $1625-1636$.

24. Nakagawa H, Yoshioka K, Miyahara E, Fukushima Y, Tamura M, Itoh K. Intrathecal administration of Y-27632, a specific Rho-associated kinase inhibitor, for rat neoplastic meningitis. Mol Cancer Res. 2005;3(8): 425-433.

25. Takeba Y, Matsumoto N, Watanabe M, et al. The Rho kinase inhibitor fasudil is involved in p53-mediated apoptosis in human hepatocellular carcinoma cells. Cancer Chemother Pharmacol. 2012;69(6): $1545-1555$.

26. Abe H, Kamai T, Hayashi K, et al. The Rho-kinase inhibitor HA-1077 suppresses proliferation/migration and induces apoptosis of urothelial cancer cells. BMC Cancer. 2014;14:412.

27. Wermke M, Camgoz A, Paszkowski-Rogacz M, et al. RNAi profiling of primary human AML cells identifies ROCK1 as a therapeutic target and nominates fasudil as an antileukemic drug. Blood. 2015;125(24): 3760-3768.

28. He H, Yim M, Liu KH, Cody SC, Shulkes A, Baldwin GS. Involvement of $\mathrm{G}$ proteins of the Rho family in the regulation of Bcl-2-like protein expression and caspase 3 activation by Gastrins. Cell Signal. 2008; 20(1):83-93. 
29. Street CA, Routhier AA, Spencer C, et al. Pharmacological inhibition of Rho-kinase (ROCK) signaling enhances cisplatin resistance in neuroblastoma cells. Int J Oncol. 2010;37(5):1297-1305.

30. Wu N, Li W, Lv Y, Shu W, Jia D. Cardioprotective effects of low-dose combination therapy with rosuvastatin and fasudil in the isolated rat heart. Pharmazie. 2014;69(9):704-708.

31. Li P, Nijhawan D, Budihardjo I, et al. Cytochrome c and dATPdependent formation of Apaf-1/caspase-9 complex initiates an apoptotic protease cascade. Cell. 1997;91(4):479-489.

32. Nakajima M, Hayashi K, Katayama K, et al. Wf-536 prevents tumor metastasis by inhibiting both tumor motility and angiogenic actions. Eur J Pharmacol. 2003;459(2-3):113-120.

33. Somlyo AV, Bradshaw D, Ramos S, Murphy C, Myers CE, Somlyo AP. Rho-kinase inhibitor retards migration and in vivo dissemination of human prostate cancer cells. Biochem Biophys Res Commun. 2000; 269(3):652-659.

34. Zhu F, Zhang Z, Wu G, et al. Rho kinase inhibitor fasudil suppresses migration and invasion though down-regulating the expression of VEGF in lung cancer cell line A549. Med Oncol. 2011;28(2):565-571.
35. Zhang Z, Ren JH, Li ZY, Nong L, Wu G. Fasudil inhibits lung carcinoma-conditioned endothelial cell viability and migration. Oncol Rep. 2012;27(5):1561-1566.

36. Brown GT, Murray GI. Current mechanistic insights into the roles of matrix metalloproteinases in tumour invasion and metastasis. J Pathol. 2015;237(3):273-281.

37. Groblewska M, Siewko M, Mroczko B, Szmitkowski M. The role of matrix metalloproteinases (MMPs) and their inhibitors (TIMPs) in the development of esophageal cancer. Folia Histochem Cytobiol. 2012; 50(1):12-19.

38. Mook OR, Frederiks WM, Van Noorden CJ. The role of gelatinases in colorectal cancer progression and metastasis. Biochim Biophys Acta. 2004;1705(2):69-89.

39. Kader AK, Liu J, Shao L, et al. Matrix metalloproteinase polymorphisms are associated with bladder cancer invasiveness. Clin Cancer Res. 2007; 13(9):2614-2620.

40. Yang X, Liu Y, Zong Z, Tian D. The Rho kinase inhibitor fasudil inhibits the migratory behaviour of 95-D lung carcinoma cells. Biomed Pharmacother. 2010;64(1):58-62.

\section{Publish your work in this journal}

Drug Design, Development and Therapy is an international, peerreviewed open-access journal that spans the spectrum of drug design and development through to clinical applications. Clinical outcomes, patient safety, and programs for the development and effective, safe, and sustained use of medicines are the features of the journal, which has also been accepted for indexing on PubMed Central. The manuscript management system is completely online and includes a very quick and fair peer-review system, which is all easy to use. Visit http://www.dovepress.com/testimonials.php to read real quotes from published authors.

Submit your manuscript here: http://www.dovepress.com/drug-design-development-and-therapy-journal 